\title{
Contribution of inflammation to the pathology of idiopathic pulmonary arterial hypertension in children
}

\author{
S Hall, ${ }^{1}$ P Brogan, ${ }^{1}$ S G Haworth, ${ }^{2}$ N Klein'
}

- Additional figures showing expression of CD3 and $\mathrm{S} 100$ and of co-localisation of BMPR2 with inflammatory markers are published online only at http:// thorax.bmj.com/content/vol64/ issueg

${ }^{1}$ Infectious Diseases and Microbiology, Institute of Child Health, London, UK;

${ }^{2}$ Department of Cardiology, Great Ormond Street Hospital for Children, London, UK

Correspondence to:

Dr S Hall, Infectious Diseases and Microbiology, Institute of Child Health, 30 Guilford Street, London WC1N 1EH, UK; s.hall@ ich.ucl.ac.uk

SGH and NK contributed equally to this work.

Received 28 August 2008 Accepted 20 May 2009 Published Online First 11 June 2009

\section{ABSTRACT}

Idiopathic pulmonary arterial hypertension (IPAH) is an incurable disease of multifactorial origin. Inflammation is frequently observed in IPAH, but its role in the pathobiology is unclear. In this study the distribution, nature and number of inflammatory cells in periarterial infiltrates in lungs of children with IPAH, pulmonary arterial hypertension associated with congenital heart disease (APAH) and in normal lung tissue were characterised and compared using immunohistochemistry The influence of treatment with combined prostacyclin and endothelin receptor blockers was also studied. In children with IPAH, both treated and untreated, but not in children with $\mathrm{APAH}$ or normal children, extensive periarterial infiltrates were present comprising macrophages and T lymphocytes with S100A4- and bone morphogenetic protein receptor type-2 (BMPR2)-positive cells. Although rarely co-expressing macrophage-specific antigens, BMPR2-positive cells were frequently closely associated with macrophages and lymphocytes. They were more abundant around peripheral arteries of children with IPAH than in APAH or normal lungs (15.1 (3.5), 2.3 (0.9) and $2.3(0.9)$ cells/mm external elastic lamina, respectively; $p<0.01$ for IPAH vs APAH or normal lungs). Prostacyclin with endothelin receptor blockade resulted in a significant reduction in endothelial cell activation as indicated by human leucocyte antigen (HLA)-DR expression (treated $17 \%$ vs untreated $100 \%, p<0.002$ ). This study shows that pulmonary inflammation is present in the lungs of children with IPAH. This may indicate a role for inflammation in the pathobiology of IPAH and provide the rationale for novel therapeutic intervention.

Idiopathic pulmonary arterial hypertension (IPAH) is a rare, incurable disorder occurring in children with a normally formed heart. It is characterised by irreversible occlusion of small pulmonary arteries resulting in a sustained increase in pulmonary arterial pressure. Death results from right heart failure. Presentation is late and in the majority of children severe structural changes have occurred in the pulmonary arteries by the time of diagnosis. Treatment with prostacyclin, sildenafil and endothelin receptor antagonists aims to dilate and remodel the pulmonary arteries. These drugs have improved survival and quality of life but are not curative, and the only therapeutic option for end-stage disease is lung transplantation.

IPAH is multifactorial in origin, and genetic and environmental factors are thought to influence the development of this disease. Mutations of members of the transforming growth factor $\beta$ (TGF $\beta$ ) family of regulatory proteins, bone morphogenetic protein type-2 receptor (BMPR2), ALK-1 and endoglin are present in a large proportion of individuals with familial ${ }^{1}$ and sporadic IPAH, ${ }^{2}$ and in patients with the inherited disorder haemorrhagic telangiectasia sometimes associated with pulmonary arterial hypertension. ${ }^{3}$ BMPR 2 expression has been reported in the macrophages of adults with IPAH. ${ }^{4}$

Endothelial dysfunction and inflammation are thought to play an important role in development of IPAH. ${ }^{5}{ }^{6}$ Endothelial dysfunction is associated with reduction in endothelium-dependent vasodilatation and enhanced vasoconstriction. Adhesion and migration of circulating inflammatory cells occur at sites of endothelial damage, but the cascade of signalling pathways resulting from such damage and the endothelial dysfunction associated with the inflammatory change are not well understood in IPAH. Normally the lung is maintained as an inflammation-free environment by a unique organisation of the immune system, ${ }^{7}$ but in adults with IPAH proinflammatory cytokines ${ }^{8}$ and platelet aggregation are enhanced. ${ }^{9}$ Circulating neutrophils from adult patients with IPAH show an amplified release of inflammatory mediators when stimulated, and this response is reduced by prostacyclin. ${ }^{10}$

Pulmonary hypertension is a common feature of congenital heart disease associated with high shear stress and endothelial dysfunction, but not with genetic and other factors known to contribute to the pathogenesis of IPAH. Endothelial damage occurs in children with congenital heart disease, ${ }^{11}$ but the contribution of an inflammatory response is unknown.

The National Pulmonary Hypertension Service for Children is based in Great Ormond Street Hospital for Children which is a paediatric cardiothoracic transplantation centre. In this study we have reviewed structural abnormalities in explanted lung tissue from children with IPAH treated with continuous intravenous prostacyclin and an endothelin receptor antagonist and compared the findings with those in archival lung tissue from untreated children. Findings in IPAH were also compared with those in APAH (pulmonary arterial hypertension associated with congenital heart disease). We used immunohistochemistry and image analysis to characterise inflammatory infiltrates in and around the pulmonary arteries noting the influence of current drug therapies on the inflammatory environment in IPAH

\section{MATERIALS AND METHODS}

Thirty-three cases were studied (table 1), 15 IPAH cases ( 8 samples taken at lung transplantation, 4 postmortem samples and 3 diagnostic lung biopsies), 9 cases of congenital heart disease with pulmonary hypertension (2 explanted samples, 1 postmortem sample and 6 diagnostic biopsies) and archival postmortem samples from 8 children and 1 adult having no cardiovascular abnormality. All 
Table 1 Grouping of samples used for immunohistochemistry

\begin{tabular}{|c|c|c|c|c|c|c|}
\hline \multirow[b]{2}{*}{$\begin{array}{l}\text { Diagnostic } \\
\text { groups }\end{array}$} & \multirow[b]{2}{*}{$\begin{array}{l}\text { No of } \\
\text { cases }\end{array}$} & \multirow[b]{2}{*}{ Age range } & \multirow{2}{*}{$\begin{array}{l}\text { Median } \\
\text { Age per } \\
\text { group }\end{array}$} & \multicolumn{3}{|l|}{ Origin of sample } \\
\hline & & & & $\begin{array}{l}\text { Biopsy (treated/ } \\
\text { untreated) }\end{array}$ & $\begin{array}{l}\text { Transplant (treated/ } \\
\text { untreated) }\end{array}$ & $\begin{array}{l}\text { Postmortem (treated/ } \\
\text { untreated) }\end{array}$ \\
\hline $\begin{array}{l}\text { Idiopathic } \\
\text { pulmonary arterial } \\
\text { hypertension }\end{array}$ & 15 & $3-16$ years & 8 years & $3(0 / 3)$ & $8(6 / 2)$ & $4(0 / 4)$ \\
\hline $\begin{array}{l}\text { Pulmonary } \\
\text { hypertensive } \\
\text { congenital heart } \\
\text { disease }\end{array}$ & 9 & $\begin{array}{l}6 \text { months-16 } \\
\text { years }\end{array}$ & 7 years & 6 & 2 & 1 \\
\hline $\begin{array}{l}\text { Normal pulmonary } \\
\text { vasculature } \pm \\
\text { infection }\end{array}$ & 9 & $\begin{array}{l}3 \text { months }-29 \\
\text { years }\end{array}$ & 8 years & & & 9 \\
\hline
\end{tabular}

tissue samples were used with the permission of the Local Research Ethics Committee of Great Ormond Street Hospital for Children (REC 05/00508/49), and, additionally, the explanted tissue was used with the explicit informed consent from the parents.

\section{Immunohistochemistry}

Sections were incubated with primary antibodies (table 2) and biotin-conjugated secondary antibodies with avidin/streptavidin amplification, and visualised with diaminobenzidine. AntiBMPR2 was a gift from Professor N Morrell (Addenbrook's NHS Foundation Trust, Cambridge UK) and anti-S100A4 was a gift from Professor N Ambartsumian (Department of Molecular Cancer Biology, Copenhagen, Denmark). Specificity of staining was controlled with an inappropriate secondary antibody and/ or by omission of the primary antibody. Slides were examined using a Leitz Dialux 20 microscope and images acquired using a Zeiss AxioCam with Axiovision software.

\section{Analysis of HLA-DR and BMPR2 staining}

Slides were anonymised to ensure blinding of scoring. The distribution of human leucocyte antigen (HLA)-DR staining in the pulmonary vasculature was assessed semi-quantitatively in 13 cases with IPAH, 8 cases with APAH and 6 normal cases. All sections were examined using a $\times 40$ objective and scored for presence or absence of positively staining cells within the intima, media and adventitia of every artery and in the alveolar capillary bed.

Quantitative analysis of BMPR2-expressing cells around preacinar and intra-acinar arteries and airways was made on 13 cases with IPAH, 5 cases with APAH and 6 normal cases. Images of 6-8 arteries and accompanying airways were made with a $\times 10$ objective. For each artery the external perimeter of the media ${ }^{12}$ was measured (Openlab, Improvision, University of Warwick, Coventry, UK) and the number of BMPR2-positive cells in the media and adventitia counted. Similarly the inner epithelial surface length of each airway was measured and BMPR2-positive cells in epithelial and submucosal layers counted. For each specimen, the results were expressed as the total number of BMPR2 cells per mm of the pooled external arterial medial length or pooled inner airway epithelial length.

\section{Immunofluorescent co-localisation}

Co-localisation of BMPR2 with cellular markers (table 2) was carried out using the method of Cattoretti (http://icg.cpmc.columbia. edu/cattoretti/Protocol/immunohistochemistry/DoubleIHC.html). Sections were examined using a fluorescent microscope (Leica Dialux) and images acquired sequentially with 494 and $547 \mathrm{~nm}$ wavelength illumination and $\times 40$ objectives. Images were merged using Openlab (Axiovision, Imaging Associates, Bicester, UK). In some samples co-localisation was confirmed by confocal microscopy (BioRad Radiance, Hemel Hempstead, UK).

\section{Statistical analysis}

Values obtained in arteries and airways from children with IPAH, APAH and normal children were compared using the two-sample test of proportion, and analysis of variance (ANOVA) with Tukey pairwise comparisons (for normally distributed data). Kruskal-Wallis and Mann-Whitney tests were used to compare non-normally distributed data.

\section{RESULTS}

\section{Histological appearance of the peripheral pulmonary arteries}

In normal children small preacinar and intra-acinar pulmonary arteries were thin walled whereas in children with IPAH many

Table 2 Antibodies used for immunohistochemistry

\begin{tabular}{|c|c|c|c|c|}
\hline Antibody & Target cell & Clone & Dilution & Supplier \\
\hline Calprotectin & Monocyte, neutrophil & MAC387 & $1: 100$ & Neomarkers* \\
\hline HLA-DR & & LN3 & $1: 50$ & Novocastra† \\
\hline CD68 & Tissue macrophage & CBL-260 & $1: 100$ & Cymbus Biotech: \\
\hline CD3 & T lymphocyte & PS1 & $1: 100$ & Novocastra $\dagger$ \\
\hline CD20 & B lymphocyte & L26 & $1: 200$ & Novocastra $\uparrow$ \\
\hline CD1A & Dendritic cell & MTB1 & $1: 25$ & Novocastra† \\
\hline CD31 & Endothelial cell & $\mathrm{JC} / 70 \mathrm{~A}$ & Prediluted & DAKO§ \\
\hline CD34 & $\begin{array}{l}\text { Endothelial and haemopoietic } \\
\text { stem cells }\end{array}$ & QBEnd10 & $1: 50$ & DAKO§ \\
\hline Ki67 & Replicating cells & MIB-1 & Prediluted & Zymed \\
\hline BMPR2 & & Rabbit polyclonal & $1: 20$ & N Morrell \\
\hline S100A4 & & Rabbit polyclonal & $1: 2000$ & N Ambartsumian \\
\hline
\end{tabular}

* Fremont, California, USA. † Newcastle upon Tyne, UK. + Chandlers Ford, UK. § Ely, UK. - San Francisco, California, USA.

BMPR2, bone morphogenetic protein type-2 receptor; HLA, human leucocyte antigen. 
were partially or completely obstructed by intimal proliferation. All IPAH sections had at least one plexiform lesion in terminal, respiratory bronchiolar or alveolar duct arteries. ${ }^{13}$ The morphology of the plexiform lesions in vasodilator-treated and untreated patients with IPAH was similar, but lesions were significantly larger in treated than in untreated children (treated, mean (SEM) 227 (7.9) $\mu \mathrm{m}$; untreated, 113.5 (7.9) $\mu \mathrm{m}, \mathrm{p}<0.001)$. A single plexiform lesion was found in $1 / 9$ cases of APAH.

\section{Inflammation of the lung periphery \\ Normal}

Seven of 9 cases showed no endothelial activation as assessed by HLA-DR (fig 1A) and S100A4 expression (Supplementary data). One child with a chest infection and one with asthma displayed patchy endothelial expression of HLA-DR and S100A4.

There was little evidence of macrophage infiltration identified by expression of either MAC387 (calprotectin) or CD68. No MAC387-labelled monocytes were found within the pulmonary artery intima or media (fig $1 \mathrm{~B}$ ). Small aggregates of $B$ and $T$ lymphocytes were present in the submucosa of small preacinar airways and bronchi but few were present in the parenchyma (Supplementary data). No CD1A-positive dendritic cells were found in the intima, media or adventitia of peripheral pulmonary arteries but they were present in the mucosa of small airways and in lymphoid aggregates associated with proximal airways.

\section{Idiopathic pulmonary arterial hypertension}

In contrast to healthy children, endothelial activation was frequent in IPAH. Endothelial expression of HLA-DR was observed in all cases with IPAH who had not received epoprostenol and bosentan treatment (table 3). It was present in patches of the alveolar capillary bed ( $8 / 8$ cases, fig $1 \mathrm{~A})$ and in small intra-acinar arteries (5/8 cases, fig $1 \mathrm{~A})$. All children, treated and untreated, expressed S100A4 on endothelial cells lining muscular arteries (15/15 cases, Supplementary data), on the alveolar walls, the arterial media and intimal proliferative regions of plexiform lesions (Supplementary data).

In all cases, treated and untreated, S100A4 was expressed by an extensive mixed infiltration of inflammatory cells. These included alveolar macrophages and a subset of circulating and migrating inflammatory cells in preacinar and intra-acinar arteries, in subendothelial regions of plexiform lesions and in the parenchyma (Supplementary data).

In all treated and untreated cases, MAC387-positive monocytes were abundant in alveolar capillaries, and MAC387- and

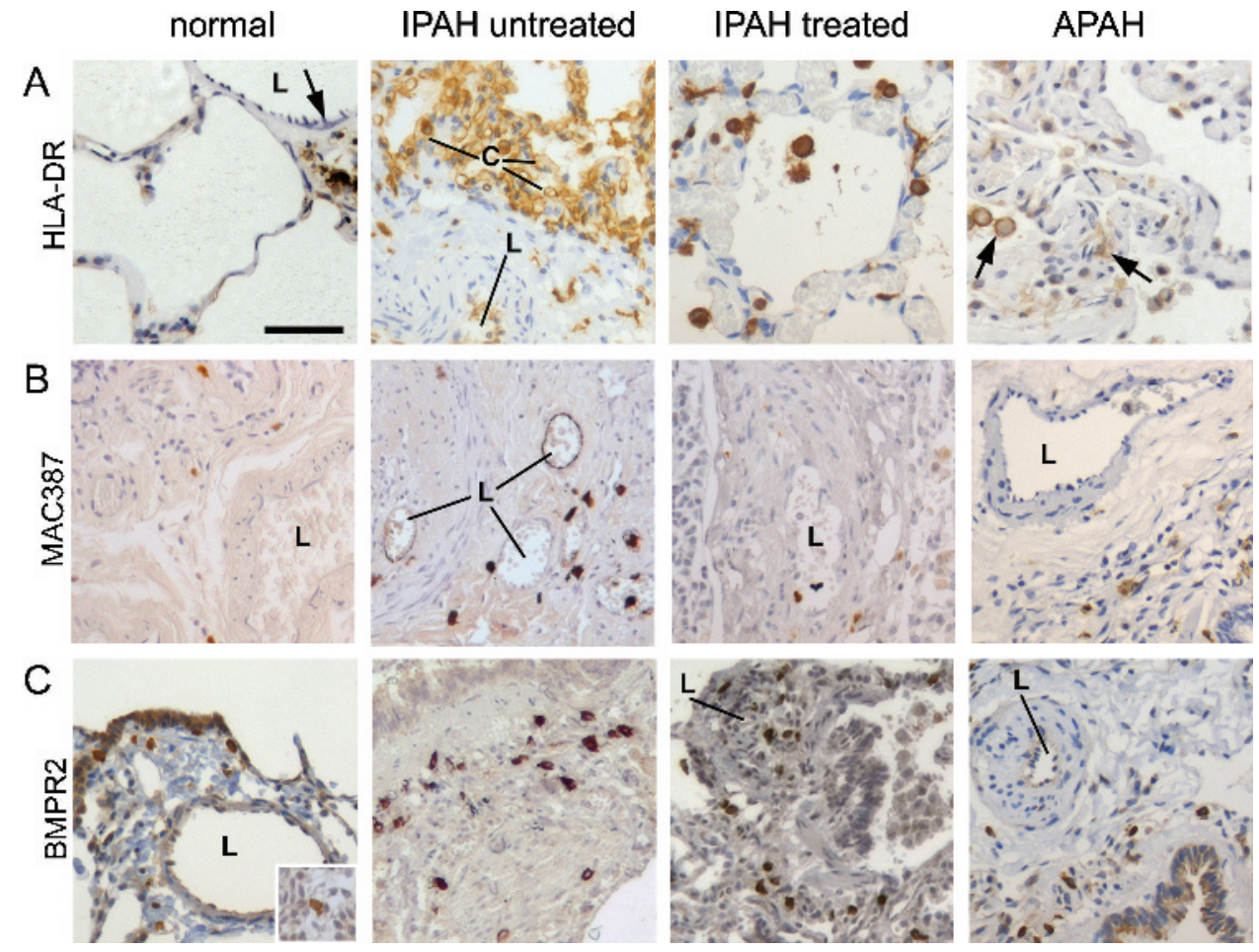

Figure 1 Immunohistochemical staining for (A) human leucocyte antigen (HLA)-DR, (B) macrophage antibody MAC387 and (C) bone morphogenetic protein type-2 receptor (BMPR2) in peripheral lung tissue from normal children, from those with idiopathic pulmonary arterial hypertension (IPAH), untreated and treated, and from children with pulmonary arterial hypertension associated with congenital heart disease (APAH). (A) In children with a normal pulmonary vasculature HLA-DR is not expressed by endothelium in alveolar capillaries or intra-acinar arteries (arrowed; $L$, lumen). In untreated children with IPAH HLA-DR is expressed by alveolar wall capillary endothelium and in small intra-acinar arteries. In contrast, in children treated with epoprostenol and bosentan no HLA-DR is detectable in the alveolar capillaries or intra-acinar arteries. In children with APAH (A) HLA-DR expression is not visible in the alveolar capillary endothelium (expressed by alveolar macrophages and circulating inflammatory cells, arrowed). (B) MAC387expressing monocytes were present in the submucosa of normal children but no endothelial expression can be detected. In untreated IPAH large numbers of circulating MAC387 (calprotectin) are observed in the wall of a plexiform lesion, and MAC387-expressing cells line some vessels (arrowed) in the intimal proliferative areas of this artery whilst unlabelled vessels are also present in the same area. In IPAH treated with epoprostenol and bosentan no MAC387 expression by endothelial cells was observed; nor was it seen in children with APAH. (C) BMPR2-expressing cells were present in the submucosa of respiratory bronchioles of normal children, untreated and treated children with IPAH and APAH, and in the mesenchyme of a human fetus at 119 days gestation (inset). In all children with IPAH, both treated and untreated, BMPR2-expressing cells were also present within the media and adventitia of small partially obstructed intra-acinar arteries (arrowheads). Few were seen in arteries of normal children or those with APAH (scale bar represents $50 \mu \mathrm{m}$ for all images). 
Table 3 Number of cases with HLA-DR expression in the arterial wall

\begin{tabular}{lllll}
\hline & No & $\begin{array}{l}\text { Arterial } \\
\text { endothelium }\end{array}$ & $\begin{array}{l}\text { Regions of } \\
\text { intimal } \\
\text { proliferation }\end{array}$ & $\begin{array}{l}\text { Capillary } \\
\text { endothelium }\end{array}$ \\
\hline Normal & 6 & 0 & 0 & 1 \\
IPAH untreated & 8 & 4 & 6 & 8 \\
IPAH, epoprostenol and & 6 & 1 & 2 & 1 \\
bosentan & 9 & 0 & 1 & 1 \\
APAH & & & & \\
\hline
\end{tabular}

APAH, pulmonary arterial hypertension associated with congenital heart disease HLA, human leucocyte antigen; IPAH, idiopathic pulmonary arterial hypertension.

CD68-positive cells were found in intimal proliferative areas and the adventitia of obstructed arteries and plexiform lesions (fig 1B). In 2/8 untreated cases, MAC387 was expressed by a thin layer of endothelial cells in some vessels within plexiform lesions (fig 1B).

In all cases, treated and untreated, frequent lymphoid aggregates contained CD3- and CD20-expressing $\mathrm{T}$ and B lymphocytes. Few B lymphocytes were found around peripheral pulmonary arteries but $\mathrm{T}$ lymphocytes were frequently seen within obstructed and dilated peripheral arteries and the parenchyma (Supplementary data). The distribution of CD1Apositive dendritic cells was similar to that in control tissue.

\section{Associated pulmonary arterial hypertension}

In contrast to children with IPAH, those with APAH showed little evidence of endothelial activation (fig 1A). HLA-DRexpressing alveolar capillaries were seen in only $1 / 9$ children with APAH. Similarly, fewer S100A4-expressing cells were seen (Supplementary data). In APAH, MAC387-positive cells were abundant in the parenchyma but not in intimal proliferative areas of obstructed arteries (fig 1B). No MAC387 labelling of endothelial cells was observed. Lymphocytes and CD1A-positive cells had a similar distribution to that of normal children.

\section{BMPR2 expression}

Periarterial BMPR2-staining cells are increased in IPAH

In all samples examined from normal children and those with IPAH and APAH, cells intensely staining for BMPR2 were found in the lung parenchyma and around airways and arteries (fig 1C). These cells resembled monocytes, being rounded, 11.7 (1.7) $\mu \mathrm{m}$ in diameter and having large round nuclei. Similar cells were present in the peripheral mesenchyme of the developing lung of a normal fetus (fig 1C, inset).

Normal children and those with APAH had similar numbers of BMPR2 cells associated with arteries (mean $1.16(0.19)$ and 3.0 (1.15) cells $/ \mathrm{mm}$, respectively) (fig 2) but there were significantly more BMPR2 cells associated with arteries in children with IPAH (mean 8.8 (0.9) cells $/ \mathrm{mm}, \mathrm{p}<0.01$ for both comparisons). The density of BMPR2 cells was similar in treated and untreated children with IPAH (8.9 (1.58) and 8.7 (1.1), respectively). The number of BMPR2-expressing cells around airways was similar in normal, IPAH and APAH groups (fig 2).

BMPR2 was detectable in the endothelium and media of peripheral arteries of most normal children and those with pulmonary hypertension (IPAH and APAH).

\section{Characterisation of BMPR2-expressing cells}

Immunofluorescent co-localisation studies on 5 cases with IPAH ( 3 untreated, 2 treated) and 2 normal cases showed that BMPR2 cells did not express CD31, usually found on endothelial cells and platelets, or CD34, expressed by haemopoietic stem cells and endothelial cells (Supplementary data). In IPAH, BMPR2 cells were frequently found in close proximity to HLADR-positive cells in the obstructing arterial intima and regions of inflammation within the airway submucosa. Expression of BMPR2 by HLA-DR-positive cells was rare, but infrequently weak BMPR2 expression was observed (Supplementary data).

There was no co-expression of BMPR2 and MAC387 in macrophages within peripheral arteries, airways or alveolar walls (Supplementary data). Although the distribution of CD68expressing macrophages in the peripheral arteries, airways and parenchyma was similar to that of BMPR2 cells the latter were present in greater numbers. In all IPAH specimens, treated and untreated, a small number of BMPR2 cells co-expressed CD68; however, these stained less intensely for both proteins than adjacent cells expressing only a single protein (fig 3A).

There was no co-localisation of BMPR2 with CD3 or CD20 in IPAH or normal samples, but T lymphocytes were frequently closely associated with BMPR2 expressing cells (fig 3B).
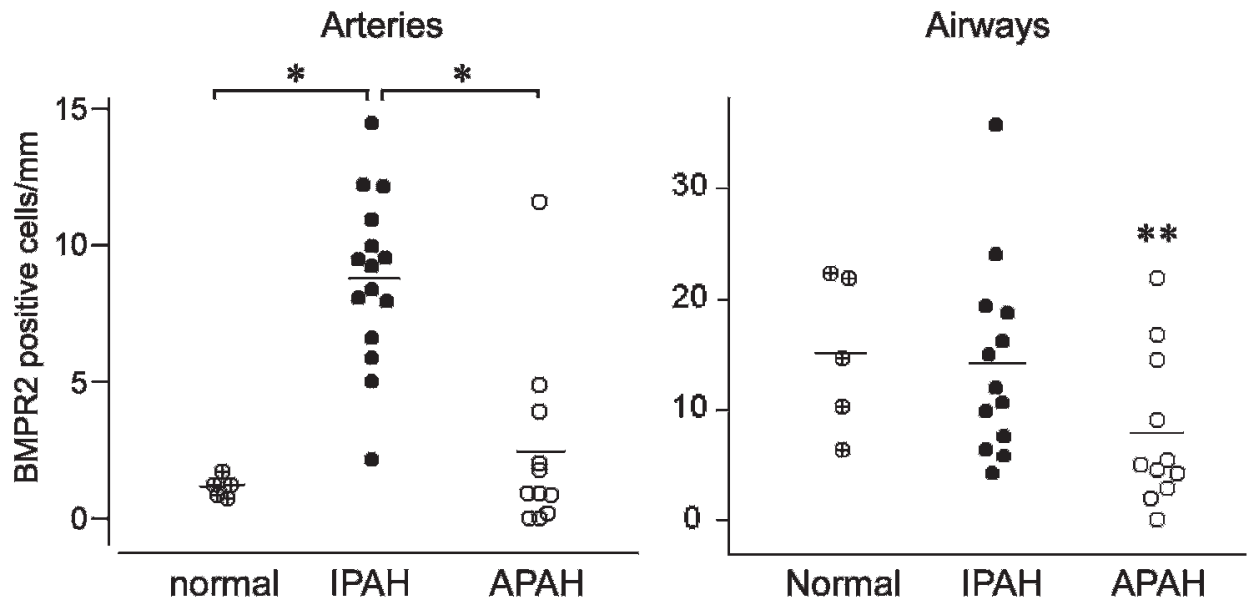

Figure 2 Dot plots showing an increase in the density of bone morphogenetic protein receptor type-2 (BMPR2)-expressing cells around pulmonary arteries of children with idiopathic pulmonary arterial hypertension (IPAH) compared with normal children and those with pulmonary arterial hypertension associated with congenital heart disease (APAH) (analysis of variance, normal vs IPAH, * $\mathrm{p}<0.01$; Mann-Whitney APH vs IPAH, $\left.{ }^{*} p<0.01\right)$. There is no difference in the density of these cells around airways of children with IPAH and normal children, but there were significantly fewer cells in children with APAH (Mann-Whitney normal vs APAH, IPAH vs APAH; ${ }^{* *} p<0.05$ ). 

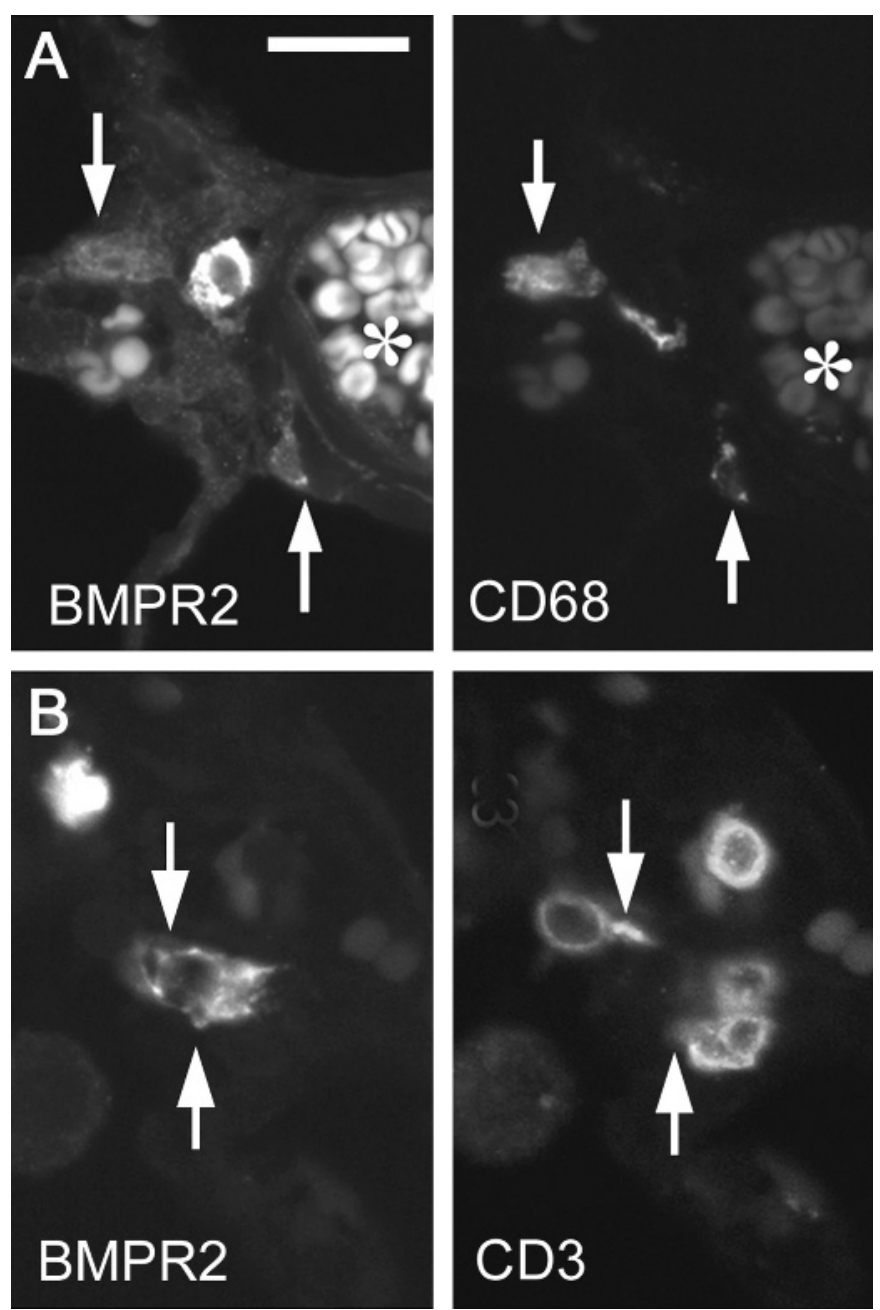

Figure 3 Characterisation of bone morphogenetic protein receptor type-2 (BMPR2)-expressing cells. Immunofluorescent labelling shows (A) coexpression of BMPR2 and CD68 in cells that have only weak BMPR2 expression (arrowed). (B) BMPR2-expressing cells are often seen in close association with CD3-expressing T lymphocytes. In A, clumps of erythrocytes autofluorescing at excitation wavelengths of both 494 and $547 \mathrm{~nm}\left({ }^{*}\right)$ are visible within the artery lumen (scale bar represents $20 \mu \mathrm{m}$ ).

\section{Influence of prostacyclin therapy and endothelin receptor blockade on inflammation}

In this study we consistently found large numbers of inflammatory and BMPR2-expressing cells in peripheral arteries of all IPAH patients who had received treatment (fig 1C) and in all those who had not (figs $1 \mathrm{~A}$ and 3 ). There was, however, less evidence of endothelial activation in treated than untreated cases. HLA-DR expression was found in the capillary endothelium of only $1 / 6$ of the treated IPAH cases, but was present in the capillary endothelium in all 8 untreated cases $(p=0.002$, fig $1 \mathrm{~A})$.

\section{DISCUSSION}

Our study is the first to compare the immunopathology of pulmonary arteries from children with IPAH who have and have not received treatment with combined bosentan and epoprostenol, hypothesised to stimulate arterial remodelling and repair. Studies with this combination of vasodilators have yet to be reported in adults. A study on lungs of untreated and prostacyclin-treated adults with IPAH showed an absence of remodelling with treatment, no significant change in morphology, but an increase in alveolar oedema and in inflammation. ${ }^{14}$ Here we confirm that in children receiving dual endothelin receptor blockade and prostacyclin therapy improvement in survival is not accompanied by reparative structural remodelling of the peripheral pulmonary vasculature. In contrast to adults treated with prostacyclin alone ${ }^{14}$ we observed a significant increase in the size of arterial lesions but a reduction in inflammation. We did not detect pulmonary oedema in treated or untreated children.

Inflammatory cells in the lung parenchyma and in small preacinar and intra-acinar arteries usually comprised macrophages and $T$ cells. These were frequently found close to endothelial cells expressing HLA-DR. Endothelial cell expression of major histocompatibilty (MHC) class II is inducible by cytokines, particularly interferon $\gamma$, and is consistent with active $\mathrm{T}$ cell and monocyte migration into areas of inflammation. ${ }^{15}$ BMPR2-expressing cells were present in the same region as the $T$ cells and macrophages. However, in spite of extensive immunohistochemical analysis we failed to define the origin of these cells since they did not coexpress marker proteins for undifferentiated monocytes, lymphocytes, dendritic cells or haemopoietic stem cells. Co-expression with the macrophage marker CD68 and HLA-DR was observed in only a minority of these cells.

BMPR2 polymorphisms have a role in the pathogenesis of IPAH, ${ }^{16}$ but its expression within the inflammatory infiltrate has not been explored previously. The functional significance of these cells in the lung is unknown but in mice similar BMPR2expressing cells were found in early experimental rheumatoid arthritis ${ }^{17}$ and other autoimmune diseases. When challenged with vascular endothelial growth factor (VEGF), athymic nude mice show an abnormally high susceptibility to the development of pulmonary hypertension associated with enhanced endothelial replication, perivascular inflammation and obstruction of peripheral arterioles. ${ }^{18}$ The BMP2/4 pathway is important within the thymus in $\mathrm{T}$ cell maturation where it is regulated ${ }^{19}$ via BMPR2 expressed in stromal cells. ${ }^{20}$ The close association seen here between $T$ cells and BMPR2-expressing cells would be compatible with the latter playing an active role in the development or maintenance of the inflammatory process within the lung. Although the mechanism responsible for the influx of inflammatory cells is unknown, an increase in the release of the chemokine CCL2 by endothelial cells has been reported in patients with IPAH ${ }^{6}$ and which may result in enhanced monocyte migration and inflammation.

It is currently unclear how the aetiology of IPAH in childhood differs from that in adults. Whilst the genetic basis of IPAH in some patients may be common, the age of onset is earlier and disease progression faster in children. ${ }^{21}$ Previous studies in adult humans and in mouse models have shown evidence of inflammation in $\mathrm{IPAH}^{422}{ }^{23}$ which has been linked to the pathogenesis of the condition. ${ }^{22}{ }^{24}$ The role of inflammation in paediatric disease and its role in IPAH pathogenesis remain unknown. Unlike in adults with IPAH, the early onset of an inflammatory process in childhood is likely to have an impact on lung development. This could have ramifications for treatment modalities in childhood IPAH.

In cases of pulmonary arterial hypertension associated with diseases of the immune system (e.g. HIV) and chronic inflammatory conditions, anti-inflammatory treatment can ameliorate and perhaps even reverse pulmonary vascular disease. ${ }^{25} \mathrm{~A}$ subgroup of adult patients with IPAH have circulating autoantibodies, ${ }^{26}$ suggesting a link between IPAH and connective tissue and autoimmune diseases..$^{22}$ Pulmonary hypertension associated with antineutrophil cytoplasmic antibody (ANCA) vasculitis can be improved with successful treatment of the vasculitis. ${ }^{27}$ This has been our own experience of children with pulmonary hypertension associated with vasculitis. 
In the murine monocrotaline model of pulmonary hypertension chemokine expression by periarterial inflammatory cells has been linked to localised medial hypertrophy. ${ }^{28}$ We examined the expression of S100A4, a calcium-binding protein which regulates a large range of cellular processes including proliferation ${ }^{23}$ and overexpression of which in mice results in development of pulmonary hypertension and plexiform lesions..$^{23}$ Our observation of enhanced S100A4 expression in endothelial, medial and intimal cells of arteries in children with IPAH reflect previous observations on children with $\mathrm{APAH}^{23}$ Intracellular expression of S100A4 is associated with mitogenesis and enhanced cell motility whilst stromal localisation is associated with angiogenesis. ${ }^{29}{ }^{30}$ Both these pathways are associated with the pathology of IPAH.

The cause of inflammatory infiltration around peripheral arteries is unknown. It is unclear if this is a primary instigating insult in the development of IPAH or reflects a repair mechanism secondary to primary endothelial damage. Impaired endothelial regeneration has been observed in a murine model of IPAH. ${ }^{31}$ Alternatively, intercurrent infection cannot be excluded as an explanation of the inflammatory response but seems unlikely as it affected predominantly the children with IPAH not those with APAH, and none had clinical evidence of a respiratory tract infection to account for our observations.

We found that treatment with epoprostenol and bosentan was associated with a reduction in endothelial HLA-DR expression, a potentially important observation. The stable prostacyclin analogue treponistil inhibits the secretion of proinflammatory cytokines by alveolar macrophages, ${ }^{32}$ and endothelin receptor blockade reduces endothelial leakage and alveolar oedema in experimental endotoxic shock. ${ }^{33}$ The reduction in endothelial HLA-DR in response to these drugs may indicate that they play a role in modulating lung inflammation in addition to their known effects on the vasculature.

The principal finding of this study was the high density of inflammatory cells in the lung periphery in both treated and untreated IPAH which was not observed in normal lungs, and which was greater than that observed in APAH. This observation could have important relevance for our understanding of the pathobiology of IPAH and the effect of treatment, which results in enhanced survival but not in reparative remodelling. Whilst we do not understand the mechanisms, the present observations indicate an avenue for further investigation and possible therapeutic intervention. Certainly the findings indicate that any intercurrent respiratory tract infection should be treated vigorously in children with IPAH. Future studies addressing the cause and significance of lung inflammation in IPAH and elucidation of inflammatory modulation should be pursued as a means of ameliorating some of the pathogenic features of this fatal disease.

Competing interests: SGH has acted as a consultant and received unrestricted educational grants from Actelion, Encysive Pharmaceuticals, GlaxoSmithKline and Pfizer. SH,PB and NK have no conflicts of interest.

Ethics approval: All tissue samples were used with the permission of the Local Research Ethics Committee of Great Ormond Street Hospital for Children (REC 05/ 00508/49) and, additionally, the explanted tissue was used with the explicit informed consent from the parents.

Provenance and peer review: Not commissioned; externally peer reviewed.

\section{REFERENCE}

1. Aldred MA, Machado RD, James V, et al. Characterization of the BMPR2 5' untranslated region and a novel mutation in pulmonary hypertension. Am J Respir Crit Care Med 2007;176:819-24.

2. Thomson JR, Machado RD, Pauciulo MW, et al. Sporadic primary pulmonary hypertension is associated with germline mutations of the gene encoding BMPR-II, a receptor member of the TGF-beta family. J Med Genet 2000;37:741-5.
3. Harrison $\mathbf{R E}$, Flanagan JA, Sankelo M, et al. Molecular and functional analysis identifies ALK-1 as the predominant cause of pulmonary hypertension related to hereditary haemorrhagic telangiectasia. J Med Genet 2003;40:865-71.

4. Atkinson C, Stewart S, Upton PD, et al. Primary pulmonary hypertension is associated with reduced pulmonary vascular expression of type II bone morphogenetic protein receptor. Circulation 2002;105:1672-8.

5. Massague J, Blain SW, Lo RS. TGF[beta] signaling in growth control, cancer, and heritable disorders. Cell 2000;103:295-309.

6. Sanchez 0, Marcos E, Perros F, et al. Role of endothelium-derived CC chemokine ligand 2 in idiopathic pulmonary arterial hypertension. Am J Respir Crit Care Med 2007:176:1041-7.

7. Bolger MS, Ross DS, Jiang $\mathrm{H}$, et al. Complement levels and activity in the normal and LPS-injured lung. Am J Physiol Lung Cell Mol Physiol 2007;292:L748-59.

8. Humbert M, Monti G, Brenot F, et al. Increased interleukin-1 and interleukin-6 serum concentrations in severe primary pulmonary hypertension. Am J Respir Crit Care Med 1995; 151:1628-31.

9. Nakonechnicov S, Gabbasov Z, Chazova I, et al. Platelet aggregation in patients with primary pulmonary hypertension. Blood Coagul Fibrinolysis 1996;7:225-7.

10. Rose F, Hattar K, Gakisch S, et al. Increased neutrophil mediator release in patients with pulmonary hypertension-suppression by inhaled iloprost. Thromb Haemost 2003;90:1141-9.

11. Hall SM, Haworth SG. Onset and evolution of pulmonary vascular disease in young children: abnormal postnatal remodelling studied in lung biopsies. J Pathol 1992:166:183-94.

12. Haworth SG. Pulmonary vascular disease in different types of congenital heart disease. Implications for interpretation of lung biopsy findings in early childhood. $\mathrm{Br}$ Heart J 1984;52:557-71.

13. Cool CD, Stewart JS, Werahera P, et al. Three-dimensional reconstruction of pulmonary arteries in plexiform pulmonary hypertension using cell-specific markers. Evidence for a dynamic and heterogeneous process of pulmonary endothelial cell growth. Am J Pathol 1999;155:411-9.

14. Achcar RO, Yung GL, Saffer H, et al. Morphologic changes in explanted lungs after prostacyclin therapy for pulmonary hypertension. Eur J Med Res 2006;11:203-7.

15. Klein NJ, Ison CA, Peakman M, et al. The influence of capsulation and lipooligosaccharide structure on neutrophil adhesion molecule expression and endothelial injury by Neisseria meningitidis. J Infect Dis 1996;173:172-9.

16. Morrell NW. Pulmonary hypertension due to BMPR2 mutation: a new paradigm for tissue remodeling? Proc Am Thorac Soc 2006;3:680-6.

17. Marinova-Mutafchieva L, Taylor P, Funa K, et al. Mesenchymal cells expressing bone morphogenetic protein receptors are present in the rheumatoid arthritis joint. Arthritis Rheum 2000;43:2046-55.

18. Taraseviciene-Stewart L, Nicolls MR, Kraskauskas D, et al. Absence of T cells confers increased pulmonary arterial hypertension and vascular remodeling. Am J Respir Crit Care Med 2007;175:1280-9.

19. Hager-Theodorides AL, Outram SV, Shah DK, et al. Bone morphogenetic protein 2/ 4 signaling regulates early thymocyte differentiation. J Immunol 2002;169:5496-504.

20. Bleul CC, Boehm T. BMP signaling is required for normal thymus development. J Immunol 2005;175:5213-21.

21. Barst RJ. Recent advances in the treatment of pediatric pulmonary artery hypertension. Pediatr Clin North Am 1999;46:331-45.

22. Dorfmuller $\mathbf{P}$, Perros F, Balabanian $\mathrm{K}$, et al. Inflammation in pulmonary arterial hypertension. Eur Respir J 2003;22:358-63.

23. Greenway S, van Suylen RJ, Du Marchie SG, et al. S100A4/Mts1 produces murine pulmonary artery changes resembling plexogenic arteriopathy and is increased in human plexogenic arteriopathy. Am J Pathol 2004;164:253-62.

24. Humbert M, Morrell NW, Archer SL, et al. Cellular and molecular pathobiology of pulmonary arterial hypertension. J Am Coll Cardiol 2004;43(12 Suppl S):13S-24S.

25. Montani D, Achouh L, Marcelin AG, et al. Reversibility of pulmonary arterial hypertension in HIV/HHV8-associated Castleman's disease. Eur Respir J 2005; 26:969-72.

26. Isern RA, Yaneva $M$, Weiner $E$, et al. Autoantibodies in patients with primary pulmonary hypertension: association with anti-Ku. Am J Med 1992;93:307-12

27. Launay D, Souza R, Guillevin L, et al. Pulmonary arterial hypertension in ANCAassociated vasculitis. Sarcoidosis Vasc Diffuse Lung Dis 2006;23:223-8.

28. Perros F, Dorfmuller $P$, Souza $R$, et al. Fractalkine-induced smooth muscle cell proliferation in pulmonary hypertension. Eur Respir J 2007;29:937-43.

29. Ambartsumian N, Klingelhofer J, Grigorian $\mathbf{M}$, et al. The metastasis-associated $\mathrm{Mts1}$ (S100A4) protein could act as an angiogenic factor. Oncogene 2001;20:4685-95

30. Schmidt-Hansen B, Ornas D, Grigorian M, et al. Extracellular S100A4(mts1) stimulates invasive growth of mouse endothelial cells and modulates MMP-13 matrix metalloproteinase activity. Oncogene 2004;23:5487-95.

31. Song Y, Coleman L, Shi J, et al. Inflammation, endothelial injury, and persistent pulmonary hypertension in heterozygous BMPR2-mutant mice. Am J Physiol Heart Circ Physiol 2008;295:677-90.

32. Raychaudhuri B, Malur A, Bonfield TL, et al. The prostacyclin analogue treprostinil blocks NFkappa B nuclear translocation in human alveolar macrophages. J Biol Chem 2002;277:33344-8

33. Albertini M, Ciminaghi B, Mazzola $\mathrm{S}$, et al. Improvement of respiratory function by bosentan during endotoxic shock in the pig. Prostaglandins Leukot Essent Fatty Acids 2001;65:103-8. 